\title{
WestVirginiaUniversity
}

THE RESEARCH REPOSITORY @ WVU

Graduate Theses, Dissertations, and Problem Reports

2003

\section{Years of teaching experience and descriptions of educational situations}

Dana J. Stapleford

West Virginia University

Follow this and additional works at: https://researchrepository.wvu.edu/etd

\section{Recommended Citation}

Stapleford, Dana J., "Years of teaching experience and descriptions of educational situations" (2003). Graduate Theses, Dissertations, and Problem Reports. 724.

https://researchrepository.wvu.edu/etd/724

This Thesis is protected by copyright and/or related rights. It has been brought to you by the The Research Repository @ WVU with permission from the rights-holder(s). You are free to use this Thesis in any way that is permitted by the copyright and related rights legislation that applies to your use. For other uses you must obtain permission from the rights-holder(s) directly, unless additional rights are indicated by a Creative Commons license in the record and/ or on the work itself. This Thesis has been accepted for inclusion in WVU Graduate Theses, Dissertations, and Problem Reports collection by an authorized administrator of The Research Repository @ WVU. For more information, please contact researchrepository@mail.wvu.edu. 
Years of Teaching Experience and Descriptions of Educational Situations

\section{Dana J. Stapleford}

A thesis submitted to the College of Human Resources and Education at West Virginia University in partial fulfillment of the requirements for the degree of

Master of Arts

in

Educational Psychology

Richard T. Walls

Anne H. Nardi

Deborah J. Hendricks

Department of Advanced Educational Studies

Morgantown, West Virginia

2003

Keywords: Expert Novice Differences, Objective Coding System, Descriptions of Educational Situations

Copyright 2003 Dana J. Stapleford 


\section{Abstract \\ Years of Teaching Experience and Descriptions of Educational Situations \\ Dana J. Stapleford}

This study examined the relationship between years of teaching experience and the type of descriptions given of educational situations.

Participants were certified teachers with 1 to 27 years of teaching experience and preservice teachers with 0 years of teaching experience. A coding system was developed as an objective method for extracting participants' descriptions of actions and consequences pertaining to student and teacher behavior. Results did not support the original hypothesis that a relationship would be found between years of teaching experience and the descriptions made. However, several other relationships among certain characteristics of the descriptions were found.

The typical description made by participants was found to (1) focus descriptions of causal relationships on student actions and consequences rather than on teacher actions and consequences and (2) involve more complete and detailed descriptions of student action than of teacher action. 


\section{Table of Contents}

Chapter 1-Rationale, Literature Review, and Research Question

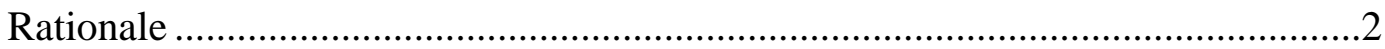

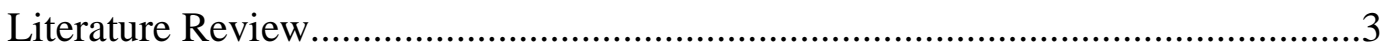

Years of teaching experience and teaching actions .................................3

Descriptions of educational situations and teaching actions.....................4

Teaching experience and types of descriptions .....................................5

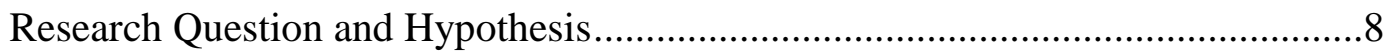

Research question .................................................................. 8

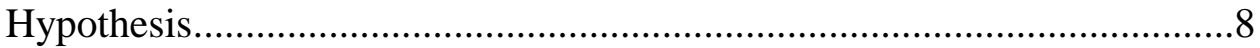

Chapter 2-Method

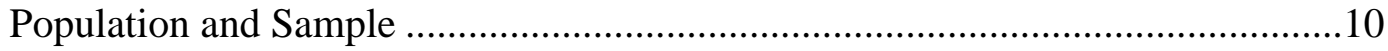

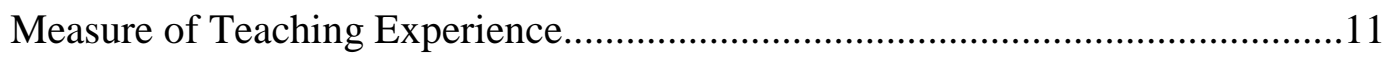

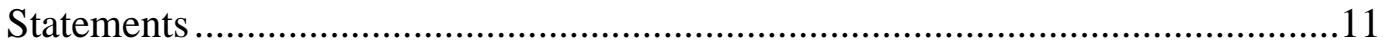

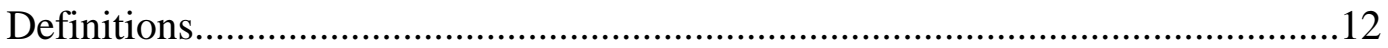

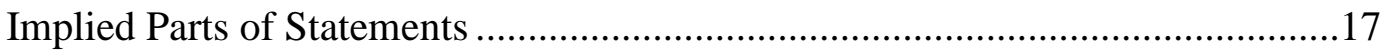

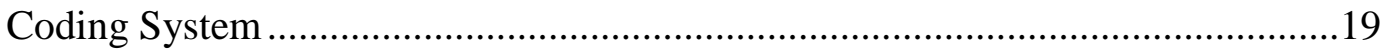

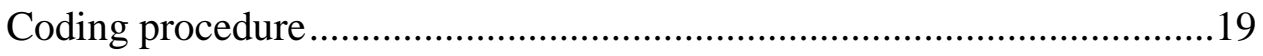

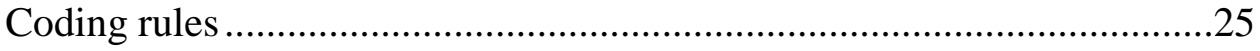

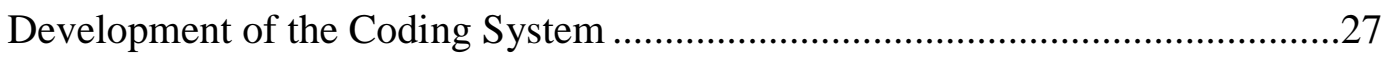

Development of the coding procedure ..............................................2

Development of the coding rules .......................................................30

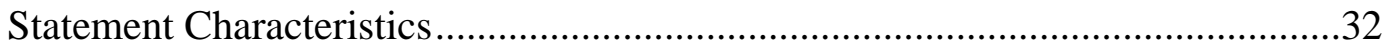




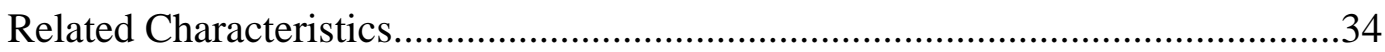

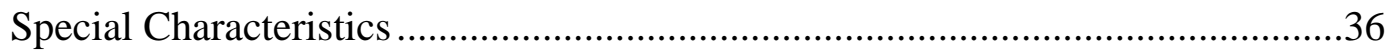

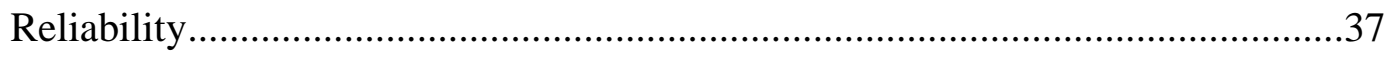

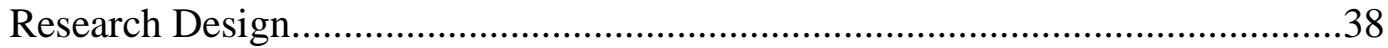

Chapter 3-Results

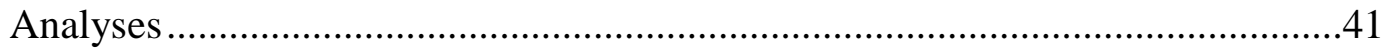

Chapter 4-Disscusion

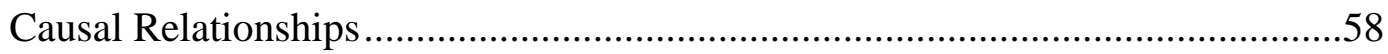

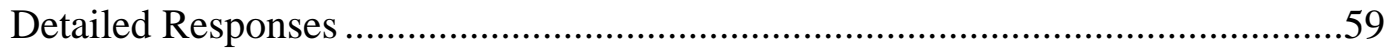

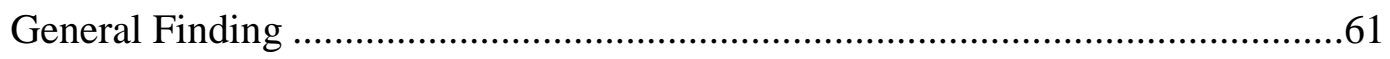

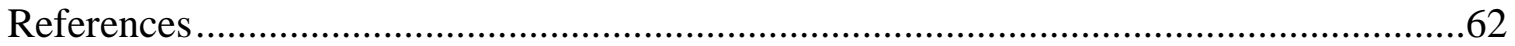

Appendices

Appendix A- Classroom Situations ......................................................64

Appendix B- Classroom Situation Questions ............................................65

Appendix C- Teacher Background Questions .............................................67 


\section{List of Tables}

Table 1: Sample of a Completed Statement Chart

Table 2: Sample of Statements Containing Consequences Coded as Immediate Under "Part (a)" of the Immediate Consequence Definition

Table 3: Sample of Statements Containing Consequences Coded as Immediate Under "Part (b)" of the Immediate Consequence Definition.

Table 4: Sample of Statements Coded With Implied (IM) Parts

Table 5: Sample of Statements Whose Consequences Were not Coded as Immediate....23

Table 6: Sample of Statements That Were Removed From Statement Charts....

Table 7: Intercoder Reliability on the Five Statement Characteristics 39

Table 8: Means and Standard Deviations for Three Groups on Statement Characteristics, Related Characteristics, and Special Characteristics

Table 9: ANOVA Results for Three Groups (Between-Subjects Independent Variable) by Four Statement Characteristics (Within-Subjects Independent Variable) on the Number of Statement Characteristics (Dependent Variable) .44

Table 10: Means, Standard Deviations, and ANOVA Results for Three Groups (Between Subjects Independent Variable) on Total Number of Statements Made (Dependent Variable)

Table 11: ANOVA Results for Three Groups (Between-Subjects Independent Variable) by Two Characteristics of Statements (Within-Subjects Independent Variable) on the Number of Characteristics (Dependent Variable). 
Table 12: ANOVA Results for Three Groups (Between-Subjects Independent Variable) by Two Special Characteristics (Within-Subjects Independent Variable) on the Number of Characteristics (Dependent Variable)

List of Figures

Figure 1: Graphical representation of the Coding Rules 


\section{Chapter 1}

Rationale, Literature Review, and Research Question

A teacher's years of teaching experience and descriptions given of educational situations have been described as important predictors of a teacher's ability to effectively alter his or her teaching actions. Much of the support for a relationship between years of teaching experience and the descriptions given of educational situations have involved researchers' interpretations of the meaning participants intended their descriptions to hold. As a result, measurements of teachers' descriptions of educational situations have not always been measured objectively. The aim of the present study was to (1) describe an objective measurement for the descriptions teachers gave of educational situations and (2) examine if a relationship was maintained between (a) years of teaching experience and (b) the type of descriptions made of an educational situation when the described measurement was used.

First, the relationship between years of teaching experience and teaching actions was examined. Then, the relationship between descriptions of educational situations and teaching actions was examined. Lastly, the relationship between teaching experience and types of descriptions was examined as it has been described in the literature. Throughout the following sections of this paper, "types of descriptions" refers to the type of details and aspects of an educational situation that are focused on by teachers in their descriptions of educational situations. "Ability to effectively alter one's teaching 
actions" refers to the alteration of classroom environments that serves to alter the probability of behavior.

Rationale

Many studies have suggested that teachers do change in terms of their approach to classroom situations across the span of their careers (Berliner, 1991). Expert teachers have been described by Leinhardt and Greeno (1986) as displaying well-practiced routines that contain more effective methods for obtaining desired responses from students than the methods used by novice teachers. Borko and Livingston (1989) further suggested that novice teachers utilized less elaborate pedagogical reasoning than did expert teachers.

It has been suggested by Berliner (1991) that although experience over time is a key factor in developing expert teaching skill, extended experience does not guarantee an expert approach to teaching. Shulman (1986) described highly effective teaching as a product of knowledge gained in several areas. One of the areas described by Shulman (1986) involved the knowledge of methods for effectively altering student behavior in desired ways.

A question then arises as to whether or not descriptions teachers give of methods for affecting or altering student behavior indicate ability to effectively alter aspects of the classroom environment in order to facilitate student learning. The focus of this paper is to examine the relationship between years of teaching experience (i.e., potential novice and expert teaching skill) and the descriptions teachers make of educational situations occurring in elementary school classrooms. The present investigation introduces a rigorous coding system for 
educational scenarios. This here-to-fore unused coding system involves type of Action, type of Consequence, Person (student or teacher), Statement Characteristics, Related Characteristics, and Special Characteristics. The use of this objective coding system may help researchers to eliminate unintended additions to the meaning recorded from teachers' descriptions of educational situations. Hence, this coding system may lead to more parsimonious examinations of the content within descriptions made by teachers of educational situations.

\section{Literature Review}

Years of teaching experience and teaching actions. The existence of a positive relationship between a teacher's ability to effectively alter his or her teaching actions and his or her total teaching experience has been supported in the literature. In the body of work pertaining to the differences between teaching performances of people with more versus less pedagogical experience, many of the differences have been credited to dissimilarities in teaching experience (Berliner, 1986). Evidence in support of the idea that years of teaching experience might predict a teacher's ability to alter his or her teaching actions comes from Samaras and Gismondi's (1998) work dealing with preservice teachers in a teacher certification program. Preservice teachers were found to be more equipped to alter their teaching actions as their experience with classroom teaching increased (Samaras \& Gismondi, 1998).

Kowalchuk (1993) offered further support that years of teaching experience has a positive relationship with effective use of pedagogical 
knowledge by teachers in altering their teaching actions. Kowalchuk compared the performance of a teacher with little experience with the performance of a teacher with a great deal of experience. In the study, the way in which existing pedagogical knowledge was applied was shown to be a clear and important reason for the vastly different teaching performances between the teachers in terms of their abilities to effectively alter their teaching actions.

Descriptions of educational situations and teaching actions. Another potential predictor of a teacher's ability to effectively alter his or her teaching actions can be examined through the type of descriptions given for educational situations (Vasquez-Levy, 1998). Blanton, Blanton, and Cross (1994) found the descriptions given by special education teachers, when compared to those given by general education teachers, to represent a more elaborate construction of teacher knowledge pertaining to the educational needs of a special needs student. This research served to suggest that pedagogical knowledge could be examined through the aspects of a situation and types of details that teachers focus on in their descriptions of educational situations. Vasquez-Levy (1998) also looked at the relationship between teacher knowledge and type of descriptions given for educational situations. Her work offered more support for the existence of a relationship between pedagogical knowledge and types of details provided within descriptions of educational settings. Vasquez-Levy's work suggests further, however, that increased pedagogical knowledge, represented by increased ability to describe the purpose behind one's own teaching actions in detail, does lead teachers to be better able to effectively alter their teaching 
actions. So, there appears to be at least some support for a relationship between a teacher's ability to describe educational situations and their ability to effectively alter their teaching actions.

As reviewed in the previous paragraphs, (a) years of teaching experience and (b) type of descriptions given of an educational situation have been suggested to be connected to a teacher's ability to effectively alter his or her teaching actions. Therefore, investigating the nature of a possible relationship between the two might offer insight into other methods for examining how the ability to alter teaching actions changes throughout a teacher's career.

Teaching experience and types of descriptions. Copeland, Birmingham, DeMeulle, D'Emidio-Caston, and Natal (1994) examined the nature of the relationship between pedagogical experience of preservice teachers and the type of descriptions they gave of an educational situation. It was found that as preservice teachers gained teaching experience, the understanding of pedagogy they expressed through descriptions of an educational vignette was characterized by an increase in the number and complexity of linked ideas pertaining to classroom teaching. For example, preservice teachers nearing the end of their certification program, when compared to preservice teachers who had not yet started the certification program "identified more causal relationships between teacher and student actions" (Copeland et al., 1994, p. 177) and "linked the specific actions they described to more generalized understandings of teaching and learning" (p.179). 
Using the general assertion from the Copeland et al. (1994) study that the way in which people describe educational situations changes with teaching experience, Copeland and D'Emidio-Caston (1998) looked to describe that change in terms of the types of statements made by people about an educational situation. Copeland and D'Emidio-Caston (1998) found that as students in a teacher certification program gained experience teaching, their descriptions of educational situations changed, and aspects of responses could be categorized into groups of different statement types. The Copeland and D'Emidio-Caston (1998) study serves as support that a relationship exits between the variables of teaching experience and type of descriptions given of an educational situation.

Each of the statement type categories that emerged in the Copeland and D'Emidio-Caston (1998) study were defined by unique characteristics of the descriptions participants gave of an educational situation. For example, the category “Practical Generalizations” (Copeland \& D’Emidio-Caston, 1998, p.521) was defined as an expression of a general condition that the participant believed to be found in many classrooms, and the category "Action Links" (p. 524) was defined as an expression of a causal relationship between the behavior of the teacher and student in the educational situation.

The purpose of determining the categories was to identify how participants interpreted educational situations. Although the categories defined specific types of descriptions that were each related to the participants' pedagogical experience, they reflected only casual interpretations of the educational situation by the teacher. The interpretations were required to meet 
unique criteria in order to be grouped into specific statement type categories, but those criteria did not include an objective measure to describe the quality of the teacher's interpretation. For example, a measure was not taken to describe the accuracy or feasibility of the causality implied between the behavior of the teacher and behavior of the student in the statements categorized as Action Links by the scorer (Copeland \& D'Emidio-Caston, 1998).

A study by Peterson and Comeaux (1987) showed similar results to those from Copeland et al. (1994) in that teaching experience was shown to share a relationship with the way educational situations were described. Peterson and Comeaux (1987) found that the teaching experience of experienced teachers as compared to student teachers was related to the number of "Level 2" (p.324) statements made which reflected higher level knowledge and ability to analyze classroom situations. Criteria used to evaluate statements were based on findings from other works dealing with differences between expert and novice patterns of problem approach and solving. Defining criteria in this way did allow for the seemingly reasonable result that a relationship was found to exist between pedagogical experience (i.e., presumed teaching expertise) and the number of Level 2 statements. However, as in the Copeland and D'EmidioCaston (1998) study, an objective measure to describe the quality of the teachers' analyses of the classroom situations was missing.

Mayer (1981) analyzed algebraic story problems into propositional structures, illustrating how confusing scenarios can be parsed to provide additional clarity for understanding such problems. The manner in which 
descriptions of educational situations in the present study were broken into smaller units of meaning resembles Mayer's (1981) division of mathematical problems into propositional structures.

Research Question and Hypothesis

Research question. Is there a significant difference between preservice teachers with no teaching experience, teachers with a moderate amount of experience, and teachers with a high level of teaching experience in the type of statements made? In this study, the relationship between (a) teaching experience and (b) the type of descriptions given of educational situations pertaining to actions and their consequences in the form of an environmental change was examined as the relationship relates to certified teachers and preservice teachers. The goals of this study were to (1) describe an objective coding system for descriptions teachers give of an educational situation and (2) examine if a relationship was maintained between (a) years of teaching experience and (b) type of descriptions made of an educational situation when the described coding system was used. The coding system measurement unit used to describe descriptions pertaining to actions and their consequences is called a "statement." Statements are defined in the Statement section.

Hypothesis. Previous work has found that relationships exist between teachers' descriptions of education situations and their years of teaching experience (Copeland, Birmingham, DeMeulle, D'Emidio-Caston, \& Natal, 1994; Copeland \& D'Emidio-Caston, 1998; Kowalchuk, 1993; Peterson \& Comeaux, 1987; Vasquez-Levy, 1998). The hypothesis of this study was that a relationship 
also would be found between the statements participants made in response to an education situation and their years of teaching experience when the Coding System defined in Coding System section was used to code responses.

Participants include teachers with varying amounts of teaching experience and students seeking teacher certification who have no teaching experience. 
Chapter 2

Method

\section{Population and Sample}

The population of this study is considered to be elementary school teachers (K-5) and preservice teachers seeking teacher certification in elementary education. The sample that was tested was drawn from a county in a mid-Atlantic state and a large university within that county. Approximately 200 public K-5 classroom teachers were contacted through their school and asked to participate. Approximately 40 preservice teachers and beginning teachers attending graduate level education courses were asked to participate. Participation was voluntary for all participants.

Current teacher participants who were contacted through their school returned their responses anonymously via the U. S. Mail. Each participant was assigned a number starting from one (1) that corresponded to when his or her response set was received. The first response set that was received was given the number one (1), the second was assigned the number two (2), and so on. In all, 20 current teachers returned responses. Preservice teachers and beginning teachers attending graduate level education courses returned their responses to their instructors. Numbers were assigned to those responses starting from 21 . In all, 11 preservice teachers and beginning teachers returned responses. The assignment of numbers was used as a means of connecting participants with their responses throughout the coding and analysis process. 


\section{Measure of Teaching Experience}

Teaching experience was measured by asking participants to indicate the number of years they had taught as classroom teachers in grades K-5 in public or private schools. Years spent teaching as a specialist (e.g., art, music, special education, or physical education) did not contribute to the years of classroom teaching experience in this investigation. Information asked for on the questionnaire pertaining to the number of education classes taken was not used. Many participants did not fill in the information completely, and several wrote comments on the questionnaire indicating that they could not recall the information asked for.

\section{Statements}

In this study, participants were given two educational situations to read and were asked to respond to open-ended questions pertaining to the situations. Parts of the responses then were coded as statements. The educational situations, titled Classroom Situations, are located in Appendix A. The openended questions, titled Classroom Situation Questions, are located in Appendix B. The questionnaire used to obtain years teaching experience is located in Appendix C.

Statements were coded from the responses participants gave to the Classroom Situation Questions. A coded statement consisted of four parts, (1) Person, (2) Action, (3) Consequence, and (4) Immediate. The manner in which statements were divided into four parts resembles Mayer's (1981) division of algebraic story problems into categories based on the general form of the 
problem. Mayer (1981) divided story problems into smaller units of meaning based on the source of the solution (i.e., formula) of the mathematical problem described in the story.

In the present study, descriptions of observable Actions and Consequences within the responses to the Classroom Situation Questions were divided into categories called statements based on the source of the Action (i.e., Person carrying out the Action). Statements were categorized as either describing student Actions and Consequences or teacher Actions and Consequences. Categories then were further distinguished based on whether or not the Consequence of the Action was Immediate.

A section of a response was coded as a statement if the four parts, (1) Person, (2) Action, (3) Consequence, and (4) Immediate, could be identified. The specific definitions of the four parts of statements were determined throughout the development of the Coding System. A statement chart was kept for each participant. Table 1 shows a sample of a completed statement chart.

\section{Definitions}

An "Action", either directly stated or Implied, was defined as a specific and observable behavior. The definition of "Implied" is provided later in the "Implied Parts of Statements" section. Part of a response containing, "check student understanding" would not be coded as an Action, for example, because it is not specific as to what would be observed if a teacher was to check student understanding. The mention of "give a sticker" would be coded as an Action 
Table 1

$\underline{\text { Sample of a Completed Statement Chart }}$

\begin{tabular}{|c|c|c|c|c|c|}
\hline$\#$ & Question & Person & Action & Consequence & Immediate \\
\hline \multirow[t]{14}{*}{20} & $1 \mathrm{~A}$ & & & none & \\
\hline & $1 \mathrm{~B}$ & teacher & keep students busy & no daydreaming & $\mathrm{X}$ \\
\hline & $1 \mathrm{~B}$ & student & physical activity & (IM) students work & \\
\hline & $1 \mathrm{~B}$ & teacher & use Power Point & (IM) students work & \\
\hline & $2 \mathrm{~A}$ & teacher & (IM) give sticker & stickers don't work & \\
\hline & $2 \mathrm{~A}$ & student & (IM) work & give extra recess & $\mathrm{X}$ \\
\hline & $2 \mathrm{~A}$ & student & (IM) work & give pass to sit with friend & $X$ \\
\hline & $2 \mathrm{~B}$ & student & working & reward & $\mathrm{X}$ \\
\hline & $3 \mathrm{~A}$ & student & don't practice & (IM) not successful & \\
\hline & $3 \mathrm{~A}$ & student & don't go over facts & leveled off & \\
\hline & $3 B$ & teacher & remove time element & (IM) increase performance & \\
\hline & $3 \mathrm{~B}$ & teacher & give drills & (IM) increase performance & \\
\hline & $4 \mathrm{~A}$ & student & engage in skill & improvement & \\
\hline & $4 \mathrm{~A}$ & student & mix up problems & student's don't memorize & \\
\hline
\end{tabular}


because "give sticker" specifies a specific observable action. Mention of the use of a specific tool was considered to be an Action as well. For example, "use flash cards" would be coded as an Action because flashcards are a specific tool, and their use could be observed.

The "Person" column was used to identify the person who carried out the Action part of the statement. In all cases, the Person was recorded as either "teacher" or "student." For example, a section of a response containing "I would give students stickers" contains the Action "give sticker". The person carrying out the Action in this case is the teacher. Therefore, "teacher" would be coded as the Person of the statement.

A "Consequence", either directly stated or Implied, was defined as affecting the external environment of the Person as an observable event that occurred after the Action listed in the statement.

The following example illustrates the application of the Consequence definition. Participant 11 wrote "if they take it home, someone will help them with it" in response to Question 1A. Within the response, "it" referred to work assigned in class. The Action "take work home" was recorded from the response along with the Consequence "help at home" and Person "student." "Help at home" was coded as the Consequence because "help at home" affects the external environment of the "student" and is an observable event that occurs after the Action "take work home."

An "Immediate Consequence" was defined as either (a) the natural consequence of the behavior described as the Action or (b) a consequence that 
had been established previously in the Classroom Situations or by the participant in their response to be contingent upon the behavior described as the Action. Consequences that automatically occurred immediately following the Action were coded as Immediate Consequences under "Part (a)" of the Immediate Consequence definition. For example, Participant 11 wrote "checking their own work enabled them to see the correct answer for immediate feedback" in response to Question 4A. From the response, the Action "check own work," the Person "student," and the Consequence "see the correct answer" were recorded. "See the correct answer" occurs automatically as a consequence of checking one's own work. The Consequence of "see the correct answer" was not arranged to be contingent upon "check own work" by the teacher; it is just the naturally occurring result of a certain behavior. This statement along with two other examples of Consequences coded as Immediate under "Part (a)" of the Immediate Consequence definition are shown in Table 2.

A Consequences that had been established previously in the Classroom Situations or by the participant in their response to be contingent upon the behavior described as the Action was coded as an Immediate Consequences under "Part (b)" of the Immediate Consequence definition. For example, Participant 03 wrote, "I would give a sticker if the work was completed" in response to Question 1B. From the response, the Action "completed work," the Person "student," and the Consequence "sticker " were recorded. Since the Participant established that getting a "sticker" would be contingent on the Action "completed work," the Consequence was coded as Immediate. The coding of the 
Table 2

Sample of Statements Containing Consequences Coded as Immediate Under "Part (a)" of the Immediate Consequence Definition

\begin{tabular}{cccccc} 
\# & Question & Person & Action & Consequence & Immediate \\
\hline 3 & 1B & student & complete homework & no homework & $\mathrm{X}$ \\
11 & $4 \mathrm{~A}$ & student & check own work & see correct answer & $\mathrm{X}$ \\
19 & $4 \mathrm{~A}$ & student & (IM) do quiz & see results & $\mathrm{X}$ \\
\hline
\end{tabular}


above statement, as well as two other examples of Consequences coded as Immediate under "Part (b)" of the Immediate Consequence definition are shown in Table 3 Implied Parts of Statements

Many participants responded to the Classroom Situation Questions in bulleted form, often giving either just an Action or a Consequence corresponding to Consequences and Actions stated in the Classroom Situations or the Classroom Situation Questions. In the coding of bulleted answers, the Action or Consequence that was stated in the response was recorded along with what was called the corresponding "Implied" Action or "Implied" Consequence from the Classroom Situations or Classroom Situation Questions. Implied Actions and Implied Consequences were recorded with the letters IM in parenthesis (IM) to indicate they were not directly stated in the participant's response, but were directly stated within the Classroom Situations or Classroom Situation Questions.

An Implied part was defined as the one most-directly corresponding Action or Consequence that was stated directly in the Classroom Situations or Classroom Situation Questions that prompted the participant to directly state an Action or Consequence. For example, Question 4A prompted participants to give an Action of which the Consequence would be "students saw improvement." In response to Question 4A, Participant 13 wrote "some students respond to taking timed drills." In the response, the Action "take timed drills" was directly stated; therefore, it was recorded without an (IM). The Participant did not directly state a 
Table 3

Sample of Statements Containing Consequences Coded as Immediate Under "Part (b)" of the Immediate Consequence Definition

\begin{tabular}{cccccc}
\hline$\#$ & Question & Person & Action & Consequence & Immediate \\
\hline 1 & 2B & student & (IM) work & extrinsic reward & $\mathrm{X}$ \\
2 & $3 \mathrm{~A}$ & student & complete to 100\% & sticker & $\mathrm{X}$ \\
3 & 1B & student & complete work & sticker & $\mathrm{X}$ \\
\hline
\end{tabular}


Consequence of the Action "take timed drills" so the Consequence recorded for the Action was the Implied Consequence "students saw improvement."

In response to Question 2A, Participant 10 wrote, "I think there will be an increase of completion of homework." Question 2A prompted participants to give a Consequence of the Action "give stickers." The Action "give stickers" was directly stated as part of the homework and sticker policy described in the Classroom Situations and was referred to in Question 2A. The Consequence "increase completion of homework" was directly stated in the response, and therefore was not recorded with an (IM). The Participant did not directly state an Action, so the Implied Action "give sticker" was recorded. Table 4 shows the complete coding of the statements made by Participant 10 and Participant 13 that were described above.

Coding System

Coding procedure. The Coding Procedure was developed to ensure that a recorded Action, Consequence, and Person belonged in the same statement. Directly stated Actions and Consequences were recorded first from each sentence and bulleted comment. Directly stated Actions were recorded first. The Person column then was filled in with the person who carried out the Action. Next, a directly stated or Implied Consequence was recorded. The Immediate column was marked with an $\mathrm{X}$ if the recorded Consequence was either (a) the natural consequence of the recorded Action or (b) a consequence that had been established previously to be contingent upon the recorded Action. The Immediate column was left blank if the recorded Consequence was neither (a) the natural 
Table 4

$\underline{\text { Sample of Statements Coded With Implied (IM) Parts }}$

\begin{tabular}{cccccc}
\hline$\#$ & Question & Person & Action & Consequence & Immediate \\
\hline 10 & $2 \mathrm{~A}$ & teacher & (IM) give stickers increase completion of homework & \\
& & & & & \\
13 & $4 \mathrm{~A}$ & student & take timed drill & (IM) students saw improvement & $\mathrm{X}$ \\
\hline
\end{tabular}


consequence of the recorded Action nor (b) a consequence that had been established previously to be contingent upon the recorded Action.

When a directly stated Consequence was found without an accompanying directly stated Action, it became the first part of the statement to be recorded. The Action column then was filled in with the corresponding Implied Action that was stated either in the question or the Classroom Situations. The Person column then was filled in with the person who carried out the recorded Action. Lastly, the Immediate column was filled in.

The coding of Consequences as Immediate was the last part of a statement to be recorded. That was done so that the necessary relationship between the recorded Action, Person, and Consequence could be carefully considered and used to guide the process of coding Consequences as Immediate or not Immediate. The following example illustrates the use of the Action, Person, and Consequence in guiding the coding of the Consequence as Immediate or not Immediate.

Participant 11 wrote, "it will have no effect" in response to Question 2A. From the response, the Implied Action "give sticker," the Person "teacher," and the Consequence "no effect " were recorded. In this case, "no effect" refers to the policy on stickers and homework having no effect as an incentive for students to work on their homework during the next class-work time. The Consequence "no effect," according to the Consequence definition, implies that it must be an observable event affecting the external environment of the teacher. The Consequence "no effect" would not take the form of an observable event 
affecting the external environment of the teacher until the next class-work time. Due to the time delay between the Action and Consequence, "no effect" does not fall under "Part (a)" of the Immediate Consequence definition, which requires a Consequence to occur directly following an Action. The Consequence "no effect" also fails to satisfy "Part (b)" of the Immediate Consequence definition because it was not previously established to be contingent on the Action "give sticker." The Immediate column in both statements was left blank to indicate that the recorded Consequence in each statement was not Immediate. Table 5 shows the coding of the above statement as well as another statement whose Consequence was not coded as Immediate for similar reasons.

Certain "ambiguous" parts of responses often could have been coded as either the Action or the Consequence part of a statement depending on who was listed in the Person column. Generally in such cases, coding the Person of a statement as "student" also meant that the statement fell under "Part (b)" of the Immediate Consequence definition.

Statements coded from ambiguous responses were coded in favor of coding the Person as "student" only if doing so would allow two conditions to be satisfied. The conditions that had to be satisfied when coding the Person as "student" from ambiguous responses were (1) the recorded Consequence of the statement was able to be coded as Immediate, and (2) the coding would not mean that words written in a participant's response would have to be altered (e.g., altering forms of verbs) to fit the coding of the statement. For example, Participant 27 wrote, "she could offer larger reinforcement prizes" in response to 
Table 5

$\underline{\text { Sample of Statements Whose Consequences Were not Coded as Immediate }}$

\begin{tabular}{cccccr}
\hline$\#$ & Question & Person & Action & Consequence & Immediate \\
\hline 11 & $2 \mathrm{~A}$ & teacher & (IM) give sticker & no effect & \\
& & & & & \\
16 & $4 \mathrm{~A}$ & student & practice & improvement & \\
\hline
\end{tabular}


Question 1B. From the response, the Implied Action "working," the Consequence "larger prizes," and the Person "student" were recorded. That statement's Consequence also was coded as Immediate under "Part (b)" of the Immediate Consequence definition. At first glance, however, it appears that "offer larger prizes" could have been recorded as the Action along with "teacher" recorded as the Person and perhaps the Implied Consequence "students work." That coding was not used because coding in favor of the Person as "student" satisfied the two ambiguous response conditions. The Consequence "larger prizes" was coded as Immediate and the words written by the Participant were not altered.

Due to the way in which ambiguous parts of responses were coded, the Coding Procedure appeared to favor coding the Person of a statement as "student." Later analysis, however, showed that student Action was recorded in statements as often as teacher Action was recorded. Therefore, the method used for coding ambiguous parts of responses did not appear to inappropriately favor the coding of student Action from responses.

In the response given by Participant 27, it sounds as though he or she intended to describe the consequence of gaining "larger prizes" to be contingent on the student's actions of "working." Basing the coding of a statement on what was assumed to be a participant's intended meaning was avoided in this study. Therefore, the participants' intended meanings were not attended to. Only the words written in the responses and the ways in which those words could be arranged to fit the Coding Rules and Coding Procedures were used throughout 
the coding of statements. The Coding Rules are described in the following section.

Coding rules. Four Coding Rules were developed for the coding of statements within a response to an individual question. The Coding Rules were developed as an objective method for coding the responses. The Coding Rules are listed below and shown graphically in Figure 1.

1.Statements within the response to an individual question that are coded with an Implied part are limited to either an Implied Action or an Implied Consequence; no statement may have more than one Implied part.

2(a). An Implied Action or Consequence may be coded with more than one directly stated Consequence or Action, respectively.

2(b). A directly stated Action or Consequence within the response to any one question may not be coded with more than one Implied Consequence or Implied Action, respectively.

3(a). A directly stated Action that is coded with a directly stated Consequence may be coded with another directly stated Consequence given within the response to an individual question.

3(b). A directly stated Action coded with a directly stated Consequence may not also be coded with an Implied Consequence within the response to a question unless the Action is written again in the response to the same question.

4(a). A directly stated Consequence coded with a directly stated Action may be coded with another directly stated Action given within the response an individual question. 


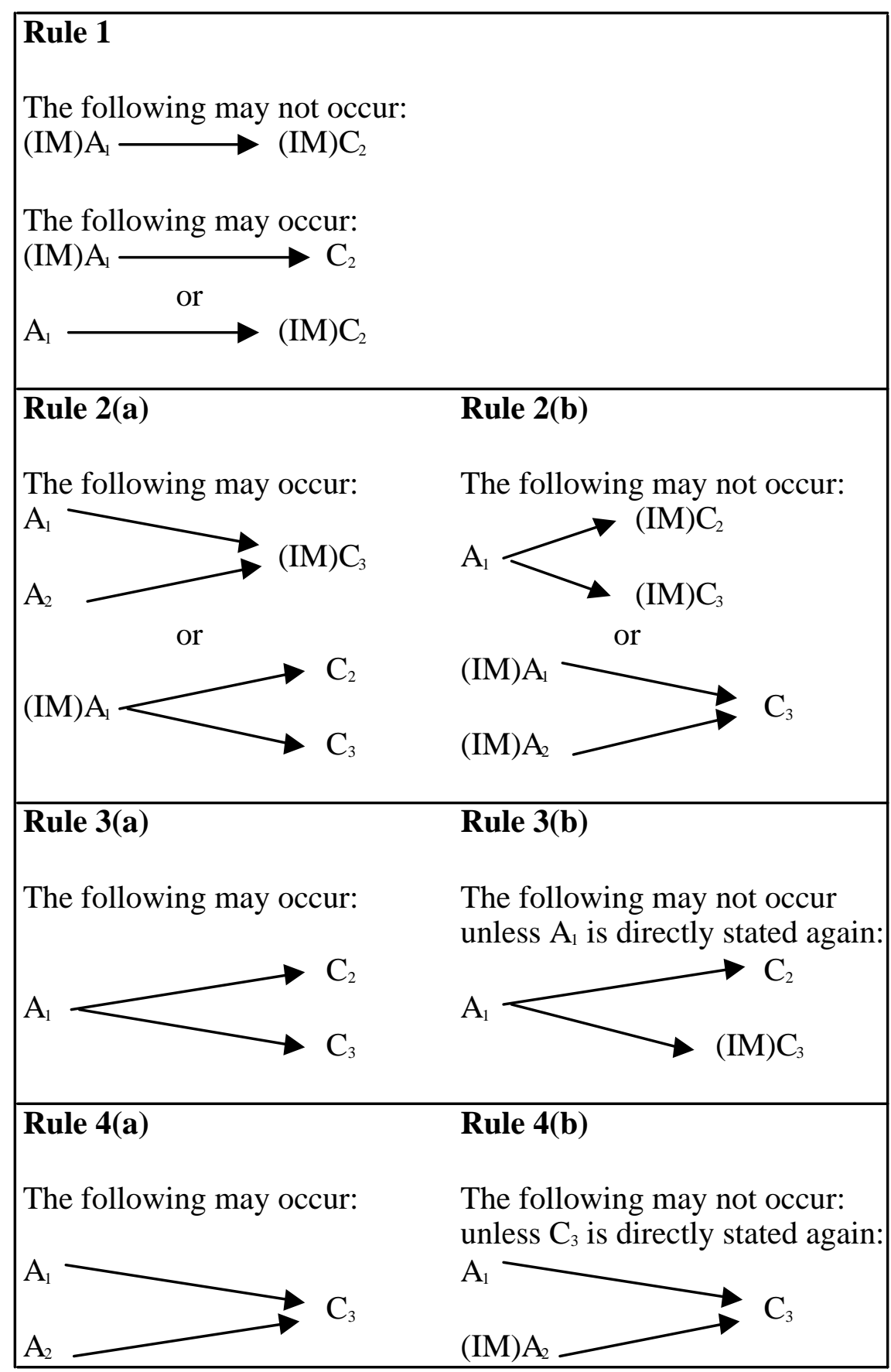

Figure 1. Graphical representation of the Coding Rules.

$\mathrm{A}_{\mathrm{n}}=$ the directly stated Action $\mathrm{n} \quad \mathrm{C}_{\mathrm{n}}=$ the directly stated Consequence $\mathrm{n}$

(IM) $\mathrm{A}_{\mathrm{n}}=$ the Implied Action $\mathrm{n} \quad(\mathrm{IM}) \mathrm{C}_{\mathrm{n}}=$ the Implied Consequence $\mathrm{n}$

$\mathrm{A} \longrightarrow \mathrm{C}: \mathrm{A}$ coded with $\mathrm{C}$ or $\mathrm{C}$ coded with $\mathrm{A}$ 
4(b). A directly stated Consequence coded with a directly stated Action may not also be coded with an Implied Action within the response to a question unless the Consequence is written again in the response to the same question. Development of the Coding System

Development of the coding procedure. Several statements that were recorded early in the coding process were later removed from the charts for violating certain parts of the definition of a Consequence. For example, Participant 10 wrote, "the reward becomes boring" in response to Question 2A. From the response, the Implied Action "give sticker," the Person "teacher," and the Consequence "boring" were recorded. One problem with the statement was that the Consequence "boring" was not stated as affecting the external environment of the Person "teacher," but rather the environment of the student. Another, more obvious problem, was that the Consequence "boring" did not meet the requirement of being an observable event. A new statement could not be coded from the responses to Question 2A that was made by Participant 10 .

Many statements had to be removed because their recorded Consequence was not an observable event occurring after the Action. If the Consequence was problematic because it did not necessarily occur after the Action, often the statement could not be saved through reorganizing the statement. In cases where the Consequence was not necessarily an event occurring after the Action, it usually was also not an observable event. For example, Participant 03 wrote, "they may not be certain of the assignment" in response to Question 1A. From the response, the Implied Action "not working," 
the Person "student," and the Consequence "not certain of assignment" were recorded. The Consequence "not certain of assignment " was not stated in the response as occurring after the Implied Action "not working," but rather as a preexisting variable that effected the probability of the occurrence of the Action "not working." The Consequence "not certain of assignment" also is problematic because it is not an observable event. A new statement could not be coded from the responses to Question 1A that was made by Participant 03. Table 6 shows the original coding of the two statements discussed in the previous paragraphs that were recorded from the responses made by Participant 03 and Participant 10.

The previous example draws attention to the fact that the coding process ignored references to non-observable discriminative stimuli described as having some control over behaviors. This was done because in all instances, such stimuli were not observable as stated by the participants. For example, Participant 17 wrote, "they lack motivation to complete assignments in class" in response to Question 1A. "Motivation" was described as a preexisting variable effecting the probability of the Action "complete assignments."

Observable variables of what was described as motivation were not provided. Coding any unobservable aspect of responses would have involved making assumptions as to what participants intended certain words such as "motivation" to describe.

Another process involving the coding of Consequences as either reinforcers or punishers of the behaviors described in the Actions of statements 
Table 6

Sample of Statements That Were Removed From Statement Charts

\begin{tabular}{|c|c|c|c|c|c|}
\hline \# & Question & Person & Action & Consequence & Immediate \\
\hline 3 & $1 \mathrm{~A}$ & student & (IM) not working & not certain of assignment & \\
\hline 10 & $2 \mathrm{~A}$ & teacher & (IM) give sticker & boring & \\
\hline
\end{tabular}


was considered. Such a process was not used, however, because it would have involved making assumptions as to the effect participants intended certain Consequences to have on Actions. For example, certain statements in which "student" was recorded as the Person could have been coded based on an assumption of the teacher's intent for the recorded Consequence to act as a reinforcer or punisher of the behavior recorded in the Action. Coding the statements in that way would force that part of the process to be based on an assumption of the teacher's intent. Also, without further information on the subsequent occurrence of the Actions (increase or decrease) recorded in a statement, it cannot be determined if the recorded Consequence actually served as a reinforcer or punisher of the behavior described in the Action.

Development of the coding rules. Rule 1 prohibits coding an Implied Action with Implied Consequence in a statement. If Implied Actions and Implied Consequences were paired, it would be possible to record statements for questions participants left blank.

Rule 2(a) addresses how coding was done of responses containing either a list of Actions or a list of Consequences without an accompanying directly stated Consequence or Action, respectively. For example, in response to Question 2A, Participant 20 listed "extra recess" and "sit with a friend" as Consequences, but did not directly state an Action that the Consequences followed. Question 2A prompted the participant to give a Consequence of the Action "do homework." "Do homework" was directly stated as part of the homework and stickers policy described in Classroom Situations and was 
referred to in Question 2A as "students' actions." From the response, two statements were coded. The Action of each statement was the Implied Action "do homework," and the Person recorded in each statement was "student." The Consequence of one statement was recorded as "extra recess." The Consequence of the other statement was recorded as "sit with a friend."

Rule 2(b) is based on the definition of Implied parts of statements. For instance, coding a directly stated Action with more than one Implied Consequence would violate the section of the definition stating that an Implied Action or Implied Consequence is the one most-directly corresponding Action or Consequence stated in the Classroom Situations or question.

Rule 3(a) describes how responses were coded that contained a directly stated Action, and two or more corresponding directly stated Consequences. For example, Participant 18 wrote "praise and encouragement to those completing [homework]" in response to Question 1B. Rule 3(a) allows for two statements to be coded from the above response. The Person recorded in both statements was "student," and the Action recorded in both statements was "completing work." The Consequence "praise" was recorded for the first statement, and the Consequence "sticker" was recorded for the second statement.

Rules 3(b) and 4(b) were created to reduce the possibility of inflated numbers of coded statements due to the coder's interpretation of the meaning or purpose of responses. For example, Participant 06 wrote, "checked own answers- students tend to inflate" in response to Question 3A. From the response, the directly stated Action "check answers" and the directly stated 
Consequence "inflated score" were recorded. Many other participants gave only directly stated Actions in response to Question 3A. In such cases, most of those statements were recorded with the Implied Consequence "increased performance." When coding the response to Question 3A given by Participant 06, it may have been tempting for the coder to also code a statement containing the directly stated Action "check answers" with the Implied Consequence "increased performance." Doing so would be an assumption on the part of the coder as to what else the participant may have intended since the response did supply a directly stated Consequence. Such assumptions were avoided in this investigation by following Coding Rule 3(b) and 4(b).

Rule 4(a) describes how responses were coded that contained a directly stated Consequence and two or more corresponding directly stated Actions. For example, Participant 07 wrote "reward students for turning homework in on time and completed correctly" in response to Question 1B. Rule 4(a) allows for two statements to be coded from the above response. The Person recorded in both statements was "student," and the Consequence recorded in both statements was the directly stated Consequence "reward." The Action "turn in homework" was recorded for the first statement, and the Action "complete work" was recorded for the second statement.

Statement Characteristics

Statements were coded by the author (Coder 1) from the participants' responses to the Classroom Situation Questions. Intercoder reliability is reported in the Reliability Section. After the statements were recorded from each of the 
participant's responses, five Statement Characteristics were counted and recorded.

Statement Characteristic 1 identified the total number of statements made. The Characteristic was found by recording the total number of statements that appeared on the statement charts.

Statement Characteristic 2 identified the number of statements made in which Consequences were coded as Immediate. The Characteristic was found by recording the total number of Xs that appeared in the Immediate column of the statement charts.

Statement Characteristic 3 identified the number of statements made with the Person coded as "student." The Characteristic was found by recording the total number of statements in which "student" was listed in the Person column on the statement charts.

Statement Characteristic 4 identified the number of statements made that did not contain Implied parts. The Characteristic was found by recording the total number of statements that appeared on the statement charts in which neither the Action nor the Consequence had an (IM) in front of it.

Statement Characteristic 5 identified the number of statements recorded from responses in which more than one directly stated Consequence was given for either a directly stated Action or Implied Action. The Characteristic was found by recording the total number of statements that appeared on the statement charts in which the same directly stated Action or Implied Action was recorded with multiple directly stated Consequences within the response to the same 
question. For example, if a directly stated Action appeared in two statements coded from a response to Question 1B and once again in a statement coded from a response to Question 2A, those three statements would contribute a 2 to the participant Statement Characteristic 5 total because only two of the statements came from the response to the same question. If, however, the same Action appeared in two statements coded from a response to Question 1B and in two statements coded from a response to Question 2A, those four statements would contribute a 4 to the Statement Characteristic 5 total.

Related Characteristics

To further examine the occurrence of the Statement Characteristics made by the participants, four "Related" Characteristics were recorded from the statement charts. The Related Characteristics were related to the Statement Characteristics previously described. A Related Characteristic was the reverse of a Statement Characteristic. Likewise, a Statement Characteristic was the reverse of a Related Characteristic. For every statement, if a Statement Characteristic could not be recorded, the reverse of the Statement Characteristic (the Related Characteristic) could be recorded. Statement Characteristic 1 (the total number of statements made) did not have a Related Characteristic because describing a reverse of the total number of statements made (Statement Characteristic 1) would not be meaningful. Therefore, a Related Characteristic 1 was not defined.

Related Characteristic 2 identified the number of statements made in which Consequences were not coded as Immediate. Related Characteristic 2 
was related to Statement Characteristic 2 (the number of statements made in which Consequences were coded as Immediate).

Related Characteristic 3 identified the number of statements made with the Person coded as "teacher." Related Characteristic 3 was related to Statement Characteristic 3 (the number of statements made with the Person coded as "student").

Related Characteristic 4 identified the number of statements made which contained Implied parts. Related Characteristic 4 was related to Statement Characteristic 4 (the number of statements made that did not contain Implied parts).

Related Characteristic 5 identified the number of statements recorded from responses in which a single directly stated Consequence was given for either a directly stated or Implied Action. Related Characteristic 5 was related to Statement Characteristic 5 (the number of statements recorded from responses in which more than one directly stated Consequence was given for either a directly stated or Implied Action).

The number of statements containing a Related Characteristic was found by subtracting the number of statements recorded on each statement chart as containing a certain Statement Characteristic from the total number of statements recorded on the statement chart. For example, Participant 29 made a total of 15 statements. Five of those 15 statements were recorded as statements in which the Consequence was coded as Immediate (Statement Characteristic 2). To find the number of statements made by Participant 29 that contained Related 
Characteristic 2 (not Immediate Consequences), five, the number of statements which contained Characteristic 2 (Immediate Consequences) was subtracted from 15, the total number of statements. Therefore, Participant 29 was recorded as making 10 statements that contained Related Characteristic 2 (not Immediate Consequences).

Special Characteristics

In addition to the Statement Characteristics and the Related Characteristics, six "Special" Characteristics were formed from combinations of the existing Characteristics. The Special Characteristics were used to describe parts of the participants' responses that contained a combination of Statement Characteristics and Related Characteristics.

Special Characteristic 1 was a combination of Statement Characteristic 3 (the number of statements made with the Person coded as "student") and Statement Characteristic 4 (the number of statements made that did not contain Implied parts). Thus, Special Characteristic 1 identified statements pertaining to student Action that did not contain Implied parts.

Special Characteristic 2 was a combination of Related Characteristic 3 (the number of statements made with the Person coded as "teacher") and Statement Characteristic 4 (the number of statements made that did not contain Implied parts). Thus, Special Characteristic 2 identified statements pertaining to teacher Action that did not contain Implied parts.

Special Characteristic 3 was a combination of Statement Characteristic 3 (the number of statements made with the Person coded as "student") and Statement Characteristic 5 (the number of statements recorded from responses 
in which more than one directly stated Consequence was given for either a directly stated or Implied Action). Thus, Special Characteristic 3 identified groups of statements in which multiple Consequences were given for a student Action.

Special Characteristic 4 was a combination of Related Characteristic 3 (the number of statements made with the Person coded as "teacher") and Statement Characteristic 5 (the number of statements recorded from responses in which more than one directly stated Consequence was given for either a directly stated or Implied Action). Thus, Special Characteristic 4 identified groups of statements in which multiple Consequences were given for a teacher Action.

Special Characteristic 5 was a combination of Statement Characteristic 3 (the number of statements made with the Person coded as "student") and Statement Characteristic 2 (the number of statements made in which Consequences were coded as Immediate). Thus, Special Characteristic 5 identified statements pertaining to an Immediate Consequence of a student Action.

Special Characteristic 6 was a combination of Related Characteristic 3 (the number of statements made with the Person coded as "teacher") and Statement Characteristic 2 (the number of statements made in which Consequences were coded as Immediate). Thus, Special Characteristic 6 identified statements pertaining to an Immediate Consequence of a teacher Action.

Reliability

To assess the reliability of the coding process, a second Coder (Coder 2) coded approximately $20 \%$ of the entire sample. Responses in the sample coded 
by Coder 2 included the responses made by two participants in Group 1, two participants in Group 2, and two participants in Group 3. Totals then were recorded from the sample for the number of statements that contributed to each of the five Statement Characteristics. A reliability score was calculated for each Statement Characteristic. The reliability scores were found by dividing (a) the sum of the agreements between Coder 1 and Coder 2 on Statement Characteristic by (b) the sum of the agreements between Coder 1 and Coder 2 on the Statement Characteristic plus the sum of the disagreements between Coder 1 and Coder 2 on the Statement Characteristics. Reliability calculations yielded reliability scores of at least .80 for all Statement Characteristics. Table 7 contains the agreements and disagreements between Coder 1 and Coder 2 and the reliability score for each Statement Characteristic.

Research Design

To see the manner in which teaching experience affected the type of statements made, years of teaching experience was divided into three Groups. Preservice teachers with no teaching experience made up Group 1, teachers with 1-7 years of experience made up Group 2, and teachers with 12-27 years of experience made up Group 3. Group 1 contained 6 preservice teachers, Group 2 contained 9 teachers, and Group 3 contained 16 teachers. Analyses then were computed to test the significance of Group membership and Characteristics of the statements on the number of Characteristics recorded from the statement charts. 
Table 7

Intercoder Reliability on the Five Statement Characteristics

Agreements Disagreements Reliability Score

Statement Characteristic 1

Total Number of Statements

99

10

0.91

Statement Characteristic 2

Immediate Consequences

35

2

0.95

Statement Characteristic 3

Student

66

6

0.92

Statement Characteristic 4

No Implied Parts

26

5

0.84

Statement Characteristic 5

Multiple Consequences

23

5

0.82 


\section{Chapter 3}

\section{Results}

It was hypothesized that a relationship would be found between the statements participants made in response to the Classroom Situation Questions and their years of teaching experience when the Coding System was used. In order to test the hypothesis, years of teaching experience was divided into Group 1 (preservice teachers with zero years of experience), Group 2 (teachers with 112 years of experience), and Group 3 (teachers with 16-27 years of experience). Analyses then were computed to examine the three Groups' scores on certain Characteristics of statements.

First, differences between the three Groups' scores on Statement Characteristic 2 (Immediate Consequences), Statement Characteristic 3 (student), Statement Characteristic 4 (no Implied parts), and Statement Characteristic 5 (multiple Consequences) were examined. Statement Characteristic 1 (total number of statements made) was not included in this analysis.

Second, differences between the three Groups' scores on Statement Characteristic 1 (total number of statements made) was examined. This analysis was computed in order to determine if the Groups differed in terms of overall quantity of statements made.

Third, a series of analyses then was computed in which differences between the three Groups' scores on a certain Statement Characteristic and the 
corresponding Related Characteristic were examined. For example, one analysis involved Statement Characteristic 2 and Related Characteristic 2.

Fourth, a series of analyses was computed in which differences were examined between the three Groups' scores on the occurrence of statements pertaining to either student Action or teacher Action that also contained a certain Characteristic of statements. Thus, each analysis involved (1) a Special Characteristic that described a certain Statement Characteristic in terms of how often that Characteristic occurred in statements that described student Action and (2) a Special Characteristic that described that same Statement Characteristic in terms of how often that Characteristic occurred in statements that described teacher Action.

Analyses

A $3 \times 4$ analysis of variance (ANOVA) was the primary analysis used to test the hypothesis that a relationship would be found between the statements participants made in response to the Classroom Situation Questions and their years of teaching experience. The analysis tested a main effect for Group membership (between-subjects variable with 3 levels), a main effect for Statement Characteristics (within-subjects variable with 4 levels), and the interaction effect. The dependent variable was number of Statement Characteristics recorded.

The four levels of Statement Characteristics used in the $3 \times 4$ analysis were Statement Characteristic 2 (the number of statements made in which Consequences were coded as Immediate), Statement Characteristic 3 (the number of statements made with the Person coded as "student"), Statement 
Characteristic 4 (the number of statements made that did not contain Implied parts), and Statement Characteristic 5 (the number of multiple Consequences given for either a directly stated Action or Implied Action). The analysis yielded $F(3,84)=29.5, p<.01$, for the Statement Characteristics main effect, indicating that significant differences in the occurrence of Statement Characteristics did exist. The Group main effect and interaction were not significant. Post-hoc comparisons for the significant Statement Characteristics main effect were not conducted. Determining which of the Statement Characteristics occurred in significantly different amounts would not be meaningful without the presence of a Group effect. Such post-hoc results would not offer information that would lead to interpretations as to why certain Statement Characteristics occurred more than others did. Due to the result that only the Statement Characteristics main effect was significant, occurrences of other Characteristics of statements across the three Groups became the focus of further analyses. Table 8 contains means and standard deviations for the three groups on Statement Characteristics, Related Characteristics, and Special Characteristics. Table 9 contains ANOVA results for the three Groups by four Statement Characteristics.

Statement Characteristic 1 was not included in the $3 \times 4$ analysis of variance described in a previous paragraph because Statement Characteristic 1 (total number of statements made) is the sum of the other four Statement Characteristics. Therefore, including it the analysis with the other four Statement Characteristics would be inappropriate. 
Table 8

Means and Standard Deviations for Three Groups on Statement Characteristics, Related

Characteristics, and Special Characteristics

\begin{tabular}{|c|c|c|c|c|c|c|c|c|}
\hline \multirow[b]{2}{*}{ Statement Characteristics } & \multicolumn{2}{|c|}{ Group 1} & \multicolumn{2}{|c|}{ Group 2} & \multicolumn{2}{|c|}{ Group 3} & \multicolumn{2}{|c|}{ Group Total } \\
\hline & M & SD & M & SD & M & SD & M & SD \\
\hline 2 Immediate Consequence & 3.67 & 2.34 & 3.78 & 1.64 & 4.06 & 2.17 & 3.90 & 2.01 \\
\hline 3 Student & 6.33 & 3.67 & 6.44 & 2.13 & 6.25 & 3.44 & 6.32 & 3.06 \\
\hline 4 No Implied Parts & 2.83 & 2.71 & 3.33 & 2.35 & 2.13 & 1.82 & 2.61 & 2.16 \\
\hline 5 Multiple Consequences & 2.67 & 2.73 & 2.00 & 2.00 & 3.00 & 2.28 & 2.65 & 2.26 \\
\hline \multicolumn{9}{|l|}{ Related Characteristics } \\
\hline 2 Not Immediate Consequence & 7.83 & 3.97 & 3.67 & 2.12 & 7.81 & 2.97 & 7.48 & 2.92 \\
\hline 3 Teacher & 5.17 & 2.32 & 4.00 & 2.12 & 5.63 & 2.75 & 5.06 & 2.53 \\
\hline 4 Implied Parts & 8.67 & 2.50 & 7.11 & 2.57 & 9.75 & 3.91 & 8.77 & 3.43 \\
\hline 5 Single Consequence & 9.17 & 3.66 & 8.44 & 2.24 & 8.88 & 2.94 & 8.81 & 2.82 \\
\hline \multicolumn{9}{|l|}{ Special Characteristics } \\
\hline 1 Student and No Implied Parts & 2.50 & 1.97 & 2.44 & 1.94 & 1.56 & 1.50 & 2.00 & 1.73 \\
\hline 2 Teacher and No Implied Parts & 1.50 & 2.81 & 0.89 & 0.78 & 0.56 & 0.81 & 0.84 & 1.39 \\
\hline 3 Student and Multiple Cons. & 2.00 & 2.53 & 1.11 & 1.05 & 1.88 & 1.82 & 1.68 & 1.78 \\
\hline 4 Teacher and Multiple Cons. & 0.67 & 1.03 & 0.89 & 1.45 & 1.13 & 1.02 & 0.97 & 1.14 \\
\hline 5 Student and Immediate Cons. & 3.33 & 2.16 & 3.22 & 1.72 & 3.50 & 1.90 & 3.39 & 1.84 \\
\hline 6 Teacher and Immediate Cons. & 0.33 & 0.52 & 0.56 & 0.73 & 0.56 & 1.03 & 0.52 & 0.85 \\
\hline
\end{tabular}


Table 9

ANOVA Results for Three Groups (Between-Subjects Independent Variable) by Four Statement Characteristics (Within-Subjects Independent Variable) on the Number of Statement Characteristics (Dependent Variable)

\begin{tabular}{llll}
\hline Source & df & MS & F \\
\hline Between-Subjects & & & \\
Groups & 2 & 0.01 & 0.01 \\
Error Between & 28 & 16.09 & \\
Within-Subjects & & & \\
Statement Characteristics & 3 & & \\
Groups X Statement Characteristics & 6 & 79.93 & $29.46^{* *}$ \\
Error Within & 84 & 2.6 & 0.96 \\
\hline
\end{tabular}

*Significant at the 0.05 level

**Significant at the 0.01 level 
A one-way ANOVA was used to examine differences among the three Groups (between-subjects independent variable) on the total number of statements made, Statement Characteristic 1 (dependent variable). The analysis yielded $F(2,28)=0.36, p>.05$ (not significant), indicating that the total number of statements made (Statement Characteristic 1) was not a function of years of teaching experience (Group membership). The means, standard deviations, and ANOVA results for the one-way analysis of variance are shown in Table 10.

To examine the occurrence of Statement Characteristics and Related Characteristics recorded from responses made by participants within the three Groups, a series of $3 \times 2$ ANOVAs was computed. Each analysis tested a main effect for Group membership (between-subjects variable with 3 levels), a main effect for Characteristics (within-subjects variable with 2 levels), and the interaction effect. Table 11 contains ANOVA results for the series of $3 \times 2$ analyses which compared Statement Characteristics and Related Characteristics.

The first $3 \times 2$ analysis examined Statement Characteristic 2 (the number of statements made in which Consequences were coded as Immediate) and Related Characteristic 2 (the number of statements made in which Consequences were not coded as Immediate). The analysis yielded $F(1,28)=36.0, p<.01$, for the Characteristics main effect, indicating that Related Characteristic 2 (not Immediate Consequences), mean $=7.48$, was recorded significantly more than Statement Characteristic 2 , mean $=3.90$. Thus, participants made more statements in which Consequences were not coded as 
Table 10

Means, Standard Deviations, and ANOVA Results for Three Groups (Between-Subjects

Independent Variable) on Total Number of Statements Made (Dependent Variable)

\begin{tabular}{|c|c|c|c|c|}
\hline Group & $\mathrm{M}$ & $\mathrm{SD}$ & & \\
\hline Group1 & 11.50 & 4.76 & & \\
\hline Group2 & 10.44 & 3.00 & & \\
\hline \multirow[t]{2}{*}{ Group3 } & 11.88 & 4.33 & & \\
\hline & \multicolumn{4}{|c|}{ ANOVA Results } \\
\hline Source & \multicolumn{2}{|c|}{$\mathrm{df}$} & MS & $\mathrm{F}$ \\
\hline
\end{tabular}

Between-Subjects

\begin{tabular}{|c|c|}
\hline Groups & 2 \\
\hline
\end{tabular}

Error Between

$28 \quad 16.7$

*Significant at the 0.05 level

**Significant at the 0.01 level 
Table 11

ANOVA Results for Three Groups (Between-Subjects Independent Variable) by Two Characteristics of Statements (Within-Subjects Independent Variable) on the Number of Characteristics (Dependent Variable)

ANOVA Results for Statement Characteristic 2 and Related Characteristic 2

\begin{tabular}{lccc}
\hline Source & df & MS & F \\
\hline Between-Subjects & & & \\
Groups & 2 & 2.97 & 0.36 \\
Error Between & 28 & 8.35 & \\
Within-Subjects & & & \\
Statement Char. 2 and Related Char. 2 & 1 & 171.57 & $36.02^{* *}$ \\
Groups X Characteristics & 2 & 1.71 & 0.36 \\
Error Within & 28 & 4.76 & \\
\hline
\end{tabular}

ANOVA Results for Statement Characteristic 3 and Related Characteristic 3

\begin{tabular}{lccc}
\hline Source & df & MS & F \\
\hline Between-Subjects & & & \\
Groups & 2 & 2.97 & 0.36 \\
Error Between & 28 & 8.35 & \\
Within-Subjects & & & \\
Statement Char. 3 and Related Char. 3 & 1 & 26.37 & 3.31 \\
Groups X Characteristics & 2 & 4.78 & 0.6 \\
Error Within & 28 & 7.98 & \\
\hline
\end{tabular}

( table continues) 
ANOVA Results for Statement Characteristic 4 and Related Characteristic 4

\begin{tabular}{lccc}
\hline Source & df & MS & F \\
\hline Between-Subjects & & & \\
Groups & 2 & 2.97 & 0.36 \\
Error Between & 28 & 8.35 & \\
Within-Subjects & & & \\
Statement Char. 4 and Related Char. 4 & 1 & 436.53 & $58.19 * *$ \\
Groups X Characteristics & 2 & 21.51 & 2.87 \\
Error Within & 28 & 7.5 & \\
\hline
\end{tabular}

ANOVA Results for Statement Characteristic 5 and Related Characteristic 5

\begin{tabular}{lccc}
\hline Source & df & MS & F \\
\hline Between-Subjects & & & \\
Groups & 2 & 3.22 & 0.36 \\
Error Between & 28 & 9.01 & \\
Within-Subjects & & & \\
Statement Char. 5 and Related Char. 5 & 1 & 520.42 & $110.61 * *$ \\
Groups X Characteristics & 2 & 0.68 & 0.15 \\
Error Within & 28 & 4.71 & \\
\hline
\end{tabular}

*Significant at 0.05 level

**Significant at 0.01 level 
Immediate (Related Characteristic 2) than statements made in which Consequences were coded as Immediate (Statement Characteristic 2). The Group main effect and the interaction were not significant. See Table 8 for means and standard deviations and Table 11 for ANOVA results.

The second $3 \times 2$ analysis examined Statement Characteristic 3 (the number of statements made pertaining to student Action) and Related Characteristic 3 (the number of statements made pertaining teacher Action). The analysis yielded $F(1,28)=3.31, p>.05$ (not significant), for the Characteristics main effect, indicating that Statement Characteristic 3 (student Action), mean $=6.32$, was not recorded a significantly different amount than Related Characteristic 3 (teacher Action), mean $=5.06$. Thus, participants made the same amount of statements pertaining to student Action (Statement Characteristic 3) as they made pertaining to teacher Action (Related Characteristic 3). The Group main effect and the interaction were not significant. See Table 8 for means and standard deviations and Table 11 for ANOVA results.

The third $3 \times 2$ analysis examined Statement Characteristic 4 (the number of statements made that did not contain Implied parts) and Related Characteristic 4 (the number of statements made that contained Implied parts). The analysis yielded $F(1,28)=58.2, p<.01$, for the Characteristics main effect, indicating that Related Characteristic 4 (Implied parts), mean $=8.77$, was recorded significantly more than Statement Characteristic 4 (no Implied parts), mean $=2.61$. Thus, participants made more statements that contained Implied parts (Related Characteristic 4) than statements that did not contain Implied parts (Statement 
Characteristic 4). The Group main effect and the interaction were not significant. See Table 8 for means and standard deviations and Table 11 for ANOVA results.

The fourth $3 \times 2$ analysis examined Statement Characteristic 5 (statements in which multiple Consequences were given for an Action) and Related Characteristic 5 (statements in which a single Consequence was given for an Action). The analysis yielded $F(1,28)=110.6, p<.01$, for the Characteristics main effect, indicating that Related Characteristic 5 (single Consequence given for an Action), mean $=8.81$, was recorded significantly more than Statement Characteristic 5 (multiple Consequences given for an Action), mean =2.65. Thus, more statements were recorded from responses in which a single directly stated Consequence was given for either a directly stated or Implied Action (Related Characteristic 5) than the number of statements recorded from responses in which more than one directly stated Consequence was given for either a directly stated or Implied Action (Statement Characteristic 5). The Group main effect and the interaction were not significant. See Table 8 for means and standard deviations and Table 11 for ANOVA results.

Characteristics of statements that occurred along with Statement Characteristic 3 (statements pertaining to student Action) and Related Characteristic 3 (statements pertaining to teacher Action) were described by the Special Characteristics. Three 3x2 ANOVAs were computed to examine the Special Characteristics. Each analysis tested a main effect for Group membership (between-subjects variable with 3 levels), a main effect for Characteristics (within-subjects variable with 2 levels), and the interaction effect. 
Table 12 contains ANOVA results for the series of $3 \times 2$ analyses which compared a given Special Characteristic with another Special Characteristic.

The first 3×2 analysis examined Special Characteristic 1 (statements pertaining to student Action that did not contain Implied parts) and Special Characteristic 2 (statements pertaining to teacher Action that did not contain Implied parts). The analysis yielded $F(1,28)=10.2, p<.01$, for the Characteristics main effect, indicating that Special Characteristic 1 (statements pertaining to student Action that did not contain Implied parts), mean $=2.00$, was recorded significantly more than Special Characteristic 2 (statements pertaining to teacher Action that did not contain Implied parts), mean $=.84$. Thus, of statements that did not contain Implied parts, significantly more of those statements were statements pertaining to student Action than teacher Action. The Group main effect and the interaction were not significant. See Table 8 for means and standard deviations and Table 12 for ANOVA results.

The second 3x2 analysis examined Special Characteristic 3 (multiple Consequences given for a student Action) and Special Characteristic 4 (multiple Consequences given for a teacher Action). The analysis yielded $F(1,28)=4.0$, p>.05 (not significant), for the Characteristics main effect, indicating that Special Characteristic 3 (multiple Consequences given for a student Action), mean = 1.68, was not recorded a significantly different amount than Special Characteristic 4 (multiple Consequences given for a teacher Action), mean $=.97$. Thus, the amount of multiple Consequence given for student Action was the same as the amount of multiple Consequence given for teacher Action. The 
Table 12

ANOVA Results for Three Groups (Between-Subjects Independent Variable) by Two Special Characteristics (Within-Subjects Independent Variable) on the Number of Characteristics (Dependent Variable)

ANOVA Results for Special Characteristic 1 and Special Characteristic 2

\begin{tabular}{lccc}
\hline Source & df & MS & F \\
\hline Between-Subjects & & & \\
Groups & 2 & 4.61 & 1.49 \\
Error Between & 28 & 3.1 & \\
Within-Subjects & & & \\
Special Char. 1 and Special Char. 2 & 1 & 18.58 & $10.18^{* *}$ \\
Groups X Characteristics & 2 & 0.49 & 0.27 \\
Error Within & 28 & 1.83 & \\
\hline
\end{tabular}

ANOVA Results for Special Characteristic 3 and Special Characteristic 4

\begin{tabular}{lccc}
\hline Source & df & MS & F \\
\hline Between-Subjects & & & \\
Groups & 2 & 1.44 & 0.55 \\
Error Between & 28 & 2.63 & \\
Within-Subjects & & & \\
Special Char. 3 and Special Char. 4 & 1 & 7.81 & 3.98 \\
Groups X Characteristics & 2 & 1.13 & 0.57 \\
Error Within & 28 & 1.96 & \\
\hline
\end{tabular}

(table continues) 
ANOVA Results for Special Characteristic 5 and Special Characteristic 6

\begin{tabular}{lccc}
\hline Source & df & MS & F \\
\hline Between-Subjects & & & \\
Groups & 2 & 0.22 & 0.1 \\
Error Between & 28 & 2.14 & \\
Within-Subjects & & & \\
Special Char. 5 and Special Char. 6 & 1 & 108.78 & $48.76^{* *}$ \\
Groups X Characteristics & 2 & 0.14 & 0.06 \\
Error Within & 28 & 2.23 & \\
\hline
\end{tabular}

*Significant at 0.05 level

**Significant at 0.01 level 
Group main effect and the interaction were not significant. See Table 8 for means and standard deviations and Table 12 for ANOVA results.

The third $3 \times 2$ analysis examined Special Characteristic 5 (statements pertaining to Immediate Consequences of a student Action) and Special Characteristic 6 (statements pertaining to Immediate Consequences of a teacher Action). The analysis yielded $F(1,28)=48.8, p<.01$, for the Characteristics main effect, indicating that Special Characteristic 5 (statements pertaining to Immediate Consequences of a student Action), mean $=3.39$, was recorded significantly more than Special Characteristic 6 (statements pertaining to Immediate Consequences of a teacher Action), mean $=.52$. Thus, the number of Immediate Consequences of a student Action was significantly greater than the number of Immediate Consequences of a teacher Action. The Group main effect and the interaction were not significant. See Table 8 for means and standard deviations and Table 12 for ANOVA results. 


\section{Chapter 4}

\section{Discussion}

Is there a significant difference between preservice teachers with no teaching experience, teachers with a moderate amount of experience, and teachers with a high level of teaching experience in the type of statements made? This original research question asked whether or not a relationship existed between teaching experience and the type of descriptions given of educational situations when the Coding System defined in the Coding System section was used. That question was examined through analyses that considered years of teaching experience (Group membership) and certain Characteristics of the statements. It was hypothesized that results of each analysis would support that a relationship exists between years of teaching experience and the descriptions made of educational situations when the Coding System was used. Results from the analyses, however, did not support the hypothesis that descriptions of educational situations were functions of years of teaching experience.

Previous work has shown that the descriptions teachers make of educational situations are related to their number of years of teaching experience (Copeland, Birmingham, DeMeulle, D’Emidio-Caston, \& Natal, 1994; Copeland \& D’Emidio-Caston, 1998; Kowalchuk, 1993; Peterson \& Comeaux, 1987; Vasquez-Levy, 1998). A possible reason as to why such a relationship was not also found in the present study involves the way descriptions were collected from the participants. The methods used for collecting descriptions in studies that 
found relationships between descriptions of educational situations and years of teaching experience were quite different from the method used in the present study. Many such studies collected descriptions of educational situations from participants over a longer period of time than was used in this study. Participants in this investigation were estimated to have spent roughly 25 minutes reading the Classroom Situations and answering the Classroom Situation Questions. Data collection in other studies reviewed involved the collection of observational data from teachers in classroom settings and the use of interview questions, as was done by Kowalchuk (1993). In studies conducted by Copeland, Birmingham, DeMeulle, D'Emidio-Caston, and Natal (1994) and Copeland and D'EmidioCaston (1998) participants spent a longer period of time responding to spoken interview questions after first viewing a video clip of an educational situation than participants of the present study spent responding to the Classroom Situation Questions. Studies that involved a longer period of data collection produced a larger body of data. Those larger bodies of data then were examined for aspects of the descriptions that were found to distinguish groups of participants based on the their number of years of experience. The short amount of time participants spent on their descriptions and the use of written responses rather than an interview may have contributed to why results of the present study did not support previous findings that years of teaching experience share a relationship with the type of descriptions made of educational situations.

Another factor that may have contributed to the lack of relationship between years of teaching experience and the type of description made of 
educational situations involves the sample size that was used. Group 1 ( 0 years of teaching experience) contained 6 participants, Group 2 (1-7 years of teaching experience) contained 9 participants, and Group 3 (12-27 years of teaching experience) contained 16 participants. With such a small number of participants in each Group (6, 9, and 16), the statistical analyses had little power, meaning that the likelihood of the analyses returning significant results was greatly reduced. Thus, the power of the analyses was likely reduced as a consequence of the small sample size.

Although the original hypothesis of the study was not supported, several other relationships among the Characteristics of statements were found. Characteristics of descriptions made of education situations, such as the content focused on and the amount of detail provided, have been described from responses made by participants with experience in teacher education courses and teaching experience ranging from 0 to over 20 years (Copeland, Birmingham, DeMeulle, D'Emidio-Caston, \& Natal, 1994). In the present study, such characteristics of descriptions of education situations also were found among the descriptions of an educational situation made by participants with experience in teacher education courses and teaching experience ranging from 0 to 27 years.

Results described the Analyses section showed that Statement Characteristics and their corresponding Related Characteristics extracted from participants' responses did occur in significantly different amounts from one another. One exception to that result involved the occurrence of statements that 
dealt with student Action (Statement Characteristic 3) and the occurrence of statements that dealt with teacher Action (Related Characteristic 3).

Results from the analysis that compared statements that dealt with student Action (Statement Characteristic 3) and statements that dealt with teacher Action (Related Characteristic 3) showed that participants spent equal amounts of time describing teacher Action and student Action. The content of those descriptions pertaining to student Action and teacher Action was quite different, however, based on the Person (student or teacher) described as carrying out Actions. In order to understand the nature of statements based on whether they dealt with student Action or teacher Action, the Special Characteristics were examined. Each Special Characteristic described a Statement Characteristic based on how often the Characteristic occurred in statements that described either teacher Action or student Action.

\section{Causal Relationships}

Teachers with various amounts of teaching experience have been found to focus much of the content of their descriptions of educational situations on causal relationships between teacher and student Actions (Copeland, Birmingham, DeMeulle, D’Emidio-Caston, \& Natal, 1994; Peterson \& Comeaux, 1987). In the present study, the recording of Immediate Consequences served as the method for identifying descriptions of causal relationships. Immediate Consequences (Statement Characteristic 2) identified Consequences that were described to immediately follow a given Action as the result of either being the naturally occurring consequence of the described Action ("Part (a)" of the 
Immediate Consequence definition) or a prior arrangement that set the Consequence to be contingent on the described Action ("Part (b)" of the Immediate Consequence definition). Therefore, descriptions of Consequences that are Immediate suggests a sensitivity to the potential effect student Actions and teacher Actions may have on themselves ("Part (a)" of the definition) and on one another ("Part (b)" of the definition).

Immediate Consequences were examined through an analysis of variance that compared Special Characteristic 5 (statements containing Immediate Consequences of student Action) and Special Characteristic 6 (statements containing Immediate Consequences of teacher Action). Results showed that when describing student Action, participants described significantly more Immediate Consequences than they did when describing teacher Action. Therefore, significantly more descriptions of Immediate Consequences were Consequences of student Action rather than teacher Action. Thus, the results imply that descriptions within the responses to the Classroom Situation Questions that dealt with student Action focused more on causal relationships between Actions and Consequences than did descriptions that dealt with teacher Action.

Detailed Responses

When describing educational situations, teachers with various amounts of teaching experience have been found to offer more detailed responses within descriptions pertaining to student Action than they offer in descriptions pertaining to teacher Action (Copeland, Birmingham, DeMeulle, D’Emidio-Caston, \& Natal, 
1994). In the present study, recording the number of statements in which multiple directly stated Consequences were given for one directly stated Action or Implied Action (Statement Characteristic 5) served as one method of measuring the amount of detail participants put into their responses. The occurrence of multiple Consequences indicated that the participant had considered a variety of potential effects a single Action could have for the Person performing the Action. Therefore, the occurrence of multiple Consequences indicated that the participant had included a considerable amount of detail pertaining to the potential effect an Action could have.

Results from the analysis that compared Special Characteristic 3 (multiple Consequences given for a student Action) with Special Characteristic 4 (multiple Consequences given for a teacher Action) showed that, as measured by multiple Consequences given for a Action, participants gave the same amount of detail in their responses when describing student Action as they gave in responses when describing teacher Action. Therefore, participants did appear to consider a variety of potential effects for a single student Action as often as they considered a variety of potential effects for a single teacher Action.

A second method of measuring the detail provided by participants in their descriptions involved the use of Implied parts of statements. Implied parts of statements were recorded when the participant stated an Action without a Consequence or stated a Consequence without an Action. The lack of Implied parts indicated that each part of the statement was directly supplied within a participant's description. Thus, statements that did not contain Implied parts 
(Statement Characteristic 4) represented descriptions that contained a substantial amount of detail.

Results from the analysis that compared Special Characteristic 1 (statements pertaining to student Action that did not contain Implied parts) and Special Characteristic 2 (statements pertaining to teacher Action that did not contain Implied parts) showed that when describing student Action, participants were more likely to directly supply all parts of statements within their responses. Therefore, as measured by lack of Implied parts (Statement Characteristic 4), participants gave more detail in their descriptions of student Action than they gave in their descriptions of teacher Action.

\section{General Finding}

The general finding of this study was that a typical type of description of an education situation made by participants with various amounts of teaching experience (ranging from 0 to 27 years) can be described based on the previously defined Coding System. The typical description made by participants (1) focused descriptions of causal relationships on student Actions and Consequences rather than on teacher Actions and Consequences and (2) involved more complete and detailed descriptions of student Action than of teacher Action. Thus, the typical description made by participants was found to be a function of the Person (student or teacher) described as carrying out an Action. 


\section{References}

Berliner, D.C. (1986). In pursuit of expert pedagogue. Educational Researcher, 15(7), 5-13.

Berliner, D.C. (1991). Educational psychology and pedagogical expertise: New opportunities for thinking about training. Educational Psychologist, 26(2), 145-155.

Blanton, L.P., Blanton, W.E., \& Cross, L.S. (1994). An exploratory study of how general and special education teachers think and make instructional decisions about students with special needs. Teacher Education and Special Education, 17(1), 62-74.

Borko, H., \& Livingston, C. (1989). Cognition and improvisation: Differences in mathematics instruction by expert and novice teachers. American Educational Research Journal, 26, 473-498.

Copeland, W.D., Birmingham, C., DeMeulle, L., D’Emidio-Caston, M., \& Natal, D. (1994). Making meaning in classrooms: Investigation of cognitive processes in aspiring teachers, experienced teachers, and their peers. American Educational Research Journal, 31(1), 166-196.

Copeland, W.D., \& D'Emidio-Caston, M. (1998). Indicators of development of practical theory in pre-service teacher education students. Teaching and Teacher Education, 14(5), 513-534.

Kowalchuk, E. (1993). Novice and expert differences in art teaching: The effects of knowledge and experience. Arts Education Policy Review. 94(5), 16. 
Leinhardt, G., \& Greeno, J. (1986). The cognitive skill of teaching. Journal of Educational Psychology, 78, 75-95.

Mayer, R.E. (1981). Frequency norms and structural analysis of algebra story problems into families, categories, and templates. Instructional Science, $10,135-175$.

Peterson, P.L., \& Comeaux, M.A. (1987). Teacher's schemata for classroom events: The mental scaffolding of teachers' thinking during classroom instruction. Teaching and Teacher Education, 3(4), 319-331.

Samaras, A.P., \& Gismondi, S. (1998). Scaffolds in the field: Vygotskian interpretation in a teacher education program. Teaching and Teacher Education, 14(7), 715-733.

Shulman, L.S. (1986). Those who understand: Knowledge growth in teaching. Educational Researcher, 15(2), 4-14.

Vasquez-Levy, D. (1998). Features of practical argument engagement. Teaching and Teacher Education, 14(5), 535-550. 


\section{Appendix A \\ Classroom Situations}

\section{Part A}

Ms. X, a $4^{\text {th }}$ grade teacher, tries always to leave a little time at the end of lessons and activities for students to work independently on their homework assignments. While students are working, she walks around monitoring progress to make sure students don't have any big problems with the assignment. Recently, she has noticed that her students don't seem to be working that hard on their assignments during the allotted time. She has repeatedly asked her students to get to work and has reminded them that the more they do in class the less they have to do at home, but her words have only temporary effects before the daydreaming starts again. Ms. X knows her class is fond of stickers, so she decides she'll offer stickers as a reward for staying on task. She tells her students the next day that if they get a certain amount of their homework completed in class, they'll get a sticker. Students turn in their homework, and the first lesson of the day begins.

\section{Part B}

Ms. Y's $5^{\text {th }}$ grade class was about to begin a unit on fractions. Ms. Y wanted to make sure that when she introduced the lessons on reducing fractions her students would be able to concentrate on the process of reducing fractions without having to spend a lot of energy thinking about the multiplication facts they would have to use. In order to make sure students would be ready for the lessons, Ms. Y started to give the class timed multiplication quizzes every day. Students would work rapidly to complete as many multiplication problems as they could in the allotted time. When finished, students marked their own papers using an answer key and recorded their scores on a chart to track their progress. Most students enjoyed trying to beat their own records and quickly improved their speed and accuracy with completing multiplication facts. A few students, however, didn't see an improvement in their speed or accuracy through taking the timed quizzes. During the weeks students were working to improve their speed and accuracy with completing multiplication problems, the class began the unit on fractions. 
Appendix B

\section{Classroom Situation Questions}

Please be specific with your answers and give details. Thank you for your participation.

Questions for Part A

1. (A) Why might the students be daydreaming rather than working on their homework?

(B) What actions do you think Ms. X should take?

2. (A) What effects do you think the new policy on stickers and homework will have on the students' actions?

(B) Why will the new policy have these effects? 


\section{Classroom Situation Questions}

Please be specific with your answers and give details. Thank you for your participation.

Questions for Part B

3. (A) Why might some of Ms. Y's students not have been successful with improving their speed and accuracy with multiplication facts through doing timed quizzes?

(B) What would you do to increase the performance of the students who did not see an improvement in their speed and accuracy with completing multiplication facts as a result of working on the timed quizzes?

4. What might have been the reason so many students saw an improvement in their scores? 


\section{Appendix C \\ Teacher Background Questions \\ Teaching Experience}

1. What is the total number of years you have taught as a classroom teacher in a K-5 grade in a public or private institution?

2. How many of those years did you serve solely as a specialist such as a special education, music, art or physical education teacher?

\section{Teacher Education}

\section{DESCRIPTION OF CLASSES FOR THIS SURVEY}

The following question refers to courses taken at a college or university in which institution credit was received either (1) after initial teacher certification or (2) for courses taken as a graduate student prior to gaining certification, but were not taken as part of a teacher certification program.

Note: Courses meeting these criteria that were also used for teacher recertification should be included in your answer to the following question.

3. Please give the total number of college or university courses THAT FIT THE ABOVE DESCRIPTION taken in the following areas and specify any related areas to the field of education that are not listed.

educational psychology, number of courses

curriculum and instruction, number of courses

special education, number of courses

classroom management, number of courses

classroom measurement, number of courses

name of related area , number of courses

name of related area number of courses

name of related area , number of courses

name of related area , number of courses

name of related area number of courses 